\title{
Tomás López Medel y sus instrucciones para defensores de Indios: una propuesta innovadora $1 /$
}

\author{
Tomas Lopez Medel and his instructions to defenders \\ of Indians: an innovative proposal
}

Caroline Cunill

Université de Toulouse IILe Mirail, Francia

Aunque en los últimos años la carrera y el pensamiento político del oidor Tomás López Medel han llamado la atención de los estudiosos, sus instrucciones para defensores de Indios han pasado desapercibidas. Sin embargo, esta innovadora propuesta es esencial para comprender cómo nació y cómo prosperó este oficio en la segunda mitad del siglo XVI. Por otra parte, también se analizarán las funciones del defensor de Indios con el fin de acercarse a los principios teóricos que sirvieron de fundamento a la creación del cargo en América.

Palabras clave: Tomás López Medel; Defensores de Indios; Relaciones interétnicas; Legislación indiana.

Although in recent years both the trajectory and the political thought of Tomás Lopez Medel have attracted the attention of several scholars, his instructions to defenders of Indians has gone unnoticed. However, the innovative proposals developed by the oidor are essential in order to highlight the construction of indigenous advocacy in the second half of the Sixteenth century. Moreover, this article also examines the defender of Indians' role, as well as the principles that underlay the creation of this office in the Americas.

KeYwords: Tomás López Medel; Defender of the Indians; Interethnic relations; Indian legislation.

1 Agradecemos a la doctora Berta Ares Queija y a los evaluadores anónimos de la revista sus sugerencias, que contribuyeron a enriquecer varios aspectos del presente trabajo. 


\section{Introducción}

Hasta hace algunos años, la figura del oidor Tomás López Medel permanecía todavía bastante relegada por la historiografía, pese a la publicación de artículos orientados principalmente hacia el análisis de su legado humanista, como fueron los de Silvio Zavala, Pilar Sanchiz Ochoa y André Saint-Lu. ${ }^{2}$ Con una perspectiva parecida, Stella María González Cicero publicó y comentó dos cartas de este letrado redactadas durante su estancia en Guatemala y dirigidas a los reyes de Bohemia. ${ }^{3}$ Fue Berta Ares Queija quien ofreció el análisis más completo, tanto de la trayectoria vital, como del pensamiento político de López Medel gracias a la recopilación, transcripción y publicación de la casi totalidad de la extensa obra de este oidor. ${ }^{4}$ No obstante, a pesar de la profundidad de los mencionados trabajos, todavía queda por analizar en detalle la labor legislativa realizada por el jurista en la Audiencia de los Confines y, posteriormente, en la del Nuevo Reino de Granada.

Esta laguna, así como el poco desarrollo de la historiografía dedicada a la cuestión de la defensoría indígena anterior a la creación del Juzgado General de indios a finales del siglo XVI, explican que las instrucciones para defensores de indios dictadas por Tomás López Medel en Santa Fe, publicadas por Berta Ares en 1993, no llegaran a ser conocidas por los especialistas de dicha institución. ${ }^{5}$ Este inmerecido olvido y el hallazgo, en el Archivo General de Indias, de otras instrucciones para defensores, que el mismo oidor promulgó durante su visita de Yucatán en 1552-1553, nos han empujado a emprender el presente trabajo en el que pretendemos, además de divulgar el texto, mostrar la trascendencia del mismo en el proceso de institucionalización de la protectoría indígena en América y esclarecer las funciones de los defensores definidas por Tomás López Medel. ${ }^{6}$

2 Sanchiz Ochoa, 1976; Zavala, 1974 y 1980; Saint-Lu, 1982.

3 González Cicero, 1980.

4 Además de la visita a la gobernación de Popayán y del tratado De los tres elementos, Berta Ares también publicó una compilación de cartas a los monarcas, leyes y ordenanzas inéditas de este oidor. Ares Queija, 1989, 1990 y 1993.

5 Instrucciones para defensores de indios de Tomás López Medel, Santa Fe, s. f., en Ares Queija, 1993, 387-390.

6 Archivo General de Indias (en adelante AGI), Justicia, 251, 644-650, instrucciones para defensores de indios del oidor Tomás López Medel, Mérida, 21 de diciembre de 1553, en apéndice. 


\section{De Yucatán al Nuevo Reino de Granada: dos versiones de las instrucciones}

Tomás López Medel empezó su carrera en la administración indiana en 1550 al llegar a Guatemala con un título de oidor de la Real Audiencia de los Confines. Poco después, se le encargó la visita general de la provincia de Yucatán, la cual realizó entre 1552 y 1553 . $^{7}$ Él dictó las primeras instrucciones para defensores de indios que conocemos en Mérida, el 21 de diciembre de 1553, durante dicha inspección. La labor legislativa que López Medel realizó en este periodo fue muy intensa, dado que también elaboró ordenanzas para pueblos de indios, lo que sugiere que las instrucciones para defensores pertenecían a un conjunto destinado a reglamentar la vida de la población indígena, tanto dentro de sus comunidades, como en sus relaciones con los españoles. ${ }^{8}$ Por otro lado, es probable que Tomás López Medel redactara las instrucciones para defensores antes de llegar a Yucatán, puesto que durante su visita de Chiapas en 1550 ya él mismo había nombrado a defensores de indios en la región. ${ }^{9}$

Las instrucciones de Santa Fe confirman la idea de que Tomás López Medel fue nombrando a esos defensores de indios y difundiendo el texto legal que reglamentaba el oficio conforme se iba desplazando por el Nuevo Mundo. Aunque las instrucciones que Berta Ares localizó en el juicio de residencia que se tomó a este jurista en 1561 no llevan fecha, fueron probablemente dictadas poco después de su llegada al Nuevo Reino de Granada con el título de oidor de esa Real Audiencia. Cabe señalar, en efecto, que en una carta al rey del 20 de diciembre de 1557 Tomás López Medel expresó la necesidad de nombrar a un defensor «que pidiese los disfavores que [los indios] han recibido de los jueces y las cédulas y provisiones que han disimulado y las malas tasas que han hecho». ${ }^{10}$ Las instrucciones debieron, pues, de acompañar el nombramiento de defensor que, según Germán Romero, se le otorgó a Martín de Agurto y Mendieta en 1557. ${ }^{11}$ Una carta de Agurto y Mendieta escrita en 1566, en la que afirmaba que

7 Acerca de la carrera indiana de Tomás López Medel, véase Ares Queija, 1993.

8 Sobre las ordenanzas para pueblos de indios de Yucatán redactadas por Tomás López Medel en 1552, ver García Bernal, 1985.

9 Declaraciones de los testigos en el juicio de residencia de Tomás López Medel, Guatemala, 1555, citadas por Ares Queija, 1993, 36. 1993, 334.

10 Tomás López Medel al monarca, Santa Fe, 20 de diciembre de 1557, en Ares Queija,

11 Germán Romero, 1960, 64-65. 
llevaba diez años ostentando el cargo de defensor de indios, viene a confirmar lo anterior. ${ }^{12}$

Dado que entre las instrucciones de Yucatán (1553) y las de Santa Fe (1557) se aprecian variaciones tanto en el ordenamiento de los capítulos, como en la introducción de precisiones, un breve análisis comparativo resulta imprescindible. Ambas versiones venían a continuación de un nombramiento de defensor - que constituía la parte introductoria del documento- y donde se definía de forma sintética la misión de este funcionario. Pero, si bien en Yucatán se hablaba de un «defensor», en Santa Fe el oidor se refería a un «defensor y procurador general». Este cambio en la denominación refleja probablemente una ampliación de jurisdicción, dado que en Yucatán el defensor sólo podía entablar pleitos civiles y en Santa Fe, en cambio, éste tenía facultad para «promover sus causas y quejas civiles y criminales». ${ }^{13} \mathrm{Y}$ es que si bien en Santa Fe se encontraba la Real Audiencia del Nuevo Reino de Granada, Mérida sólo era la capital de la gobernación de Yucatán que, en aquel entonces, dependía de la Audiencia de los Confines, situada en la ciudad de Guatemala.

En ambos textos, los dos primeros capítulos eran los más generales, dado que sintetizaban la esencia del cargo de defensor, que los demás apartados no hacían más que desarrollar. El primero, dedicado a la misión de representación indígena, se repetía de forma casi idéntica en las dos versiones. El segundo capítulo de las instrucciones de Santa Fe, que versaba sobre la obligación de informarse de los agravios perpetrados contra los naturales, incluía el noveno del texto anterior, donde se autorizaba al defensor a que fuera a los pueblos de indios para cumplir con ese requisito. Los apartados 3 y 4 de la versión de 1557 trataban de las relaciones contractuales entre indios y españoles, centrándose el tercero en los contratos laborales y el cuarto en las compraventas.

En las instrucciones de Santa Fe, los siguientes capítulos estaban dedicados al tributo indígena. En el apartado 5, el oidor sintetizó tres capítulos de la versión anterior - el quinto, el octavo y el décimo- donde se estipulaba que el defensor debía evitar que se cobraran excesivos tributos a los indios, fomentar los recuentos de tributarios y la conservación de copias de las tasaciones en los pueblos. El sexto capítulo se centraba en el necesa-

12 Martín de Agurto y Mendieta a Las Casas, Santa Fe, 15 de abril de 1566, en Friede, 1976,

13 Instrucciones para defensores de Tomás López Medel, Santa Fe, s.f., en Berta Ares, 1993, 387. 
rio control de los caciques para que no maltrataran a los indios pidiéndoles contribuciones excesivas. El apartado siguiente versaba sobre la exención de tributo indígena, en caso de que la tierra fuera estéril por culpa de desastres naturales. Finalmente, en los dos últimos capítulos de las instrucciones de 1557 - correspondientes a los apartados 11 y 7 de la versión anteriorTomás López Medel se refería al trabajo de los indios naborías que residían en las ciudades españolas y a la idolatría.

Las instrucciones de Santa Fe constituían, pues, una síntesis y reordenación del texto legislativo anterior, destinadas a mejorar su estructura lógica. Cabe señalar que el capítulo sexto de las instrucciones de Yucatán, dedicado a la huida de los naturales, no se repitió en las de Santa Fe, seguramente porque, en aquella península, las llamadas «montañas» constituían una región fuera del control colonial que atraía a los mayas descontentos, problema que no debió de existir en el Nuevo Reino. ${ }^{14}$ El dato muestra la atención que el oidor Tomás López Medel prestaba al entorno en el que deberían desenvolverse los futuros defensores. Por otro lado, aunque en el texto neogranadino faltaban dos apartados presentes en el yucateco - el 13 sobre las penas previstas en caso de que el defensor no cumpliera con su misión y el 14 acerca del salario de este funcionario-, la nueva versión aportaba precisiones en varios aspectos. Incluía, por ejemplo, tres capítulos inéditos: el décimo, sobre las estancias de ganado que perjudicaban a las comunidades indígenas; el undécimo, donde se encargaba al defensor conocer y procurar que se aplicara la legislación favorable de los naturales; y, finalmente, el duodécimo, referente a la prohibición de robar a los naturales y de sacarlos de sus pueblos.

La existencia de las instrucciones para defensores de 1553 y 1557 nos obliga, pues, a adelantar la fecha generalmente aceptada para el inicio del desarrollo de la vertiente civil de la protectoría indígena en América. Sugieren que en la década de 1550 la protectoría eclesiástica ya estaba dejando paso a la civil y que el cargo de defensor estaba más generalizado y reglamentado de lo que se ha pensado hasta la fecha. La investigación que acabamos de terminar sobre los defensores de Yucatán confirma el grado de implantación del oficio en esa provincia en la segunda mitad del siglo XVI. En efecto, hemos podido comprobar que seis personas distintas sucedieron a Hernando Muñoz Zapata en el cargo de defensor civil, de modo

14 Sobre estas regiones, véanse Farriss, 1992 y Bracamonte y Sosa, 2001. 
que, salvo algunas breves suspensiones, los nombramientos fueron ininterrumpidos entre 1553 y $1586 .{ }^{15}$

Woodrow Borah y Carmen Ruigómez Gómez recuerdan que la doble vertiente, civil y eclesiástica, del concepto de defensoría hunde sus raíces en el Bajo Medioevo europeo, puesto que la protección de las viudas, huérfanos, ancianos, enfermos y, más generalmente, de los pobres era una obligación tanto de los obispos, como del rey y sus delegados. ${ }^{16} \mathrm{Si}$ bien en América la dimensión civil de la defensa del indio se dio desde un principio - no olvidemos que, al menos en teoría, los encomenderos debían proteger a la población aborigen-, la multiplicación de los abusos empujó a la corona a encargar la defensa de los indígenas a los religiosos. De este modo, desde la década de 1530 los prelados recibieron sistemáticamente el título de protector de los naturales, así como instrucciones para el fiel cumplimiento de su cargo ${ }^{17}$ y, según Ruigómez Gómez, la etapa eclesiástica de la defensoría se habría prolongado hasta el último tercio del siglo XVI. ${ }^{18}$ Borah, por su parte, considera que, todavía en los años 1570, «el plan de dar un asesoramiento jurídico gratuito a los indios era burdamente inadecuado». ${ }^{19}$ Sin embargo, las instrucciones para defensores del oidor Tomás López Medel sugieren lo contrario, de modo que ya no se pueden considerar las ordenanzas del virrey don Francisco de Toledo de 1575 como el primer texto legal en el que se generalizaba el cargo en América, definiéndose las funciones propias del oficio..$^{20}$

\section{De las instrucciones de Tomás López Medel a las ordenanzas de Francisco de Toledo: ¿una continuidad?}

Al contrario de lo que ha ocurrido con el oidor Tomás López Medel, la obra legislativa del virrey Francisco de Toledo ha sido extensamente estudiada, ya que este gobernante pasó a la historia como «supremo organizador del Perú». ${ }^{21}$ No es extraño, pues, que a principios del siglo XX

15 Cunill, 2011.

16 Ruigómez Gómez, 1988, 37-38 y Borah, 1985, 24-27.

17 Dussel, 1970, 120; Friede, 1956, 643-655.

18 Ruigómez Gómez, 1988, 67.

19 Borah, 1985, 89.

20 Sobre la trascendencia de las ordenanzas de Toledo en la historia de la defensoría, véanse Borah, 1985, 95-96; Ruigómez Gómez, 1988, 81-87 y Bayle, 1945, 110-125.

21 Levillier, 1935-1942, Francisco de Toledo, 1986, I, XIII-LXIII y Sarabia Viejo, 1999. 
Roberto Levillier ya diera a conocer sus ordenanzas para defensores de indios y que, más recientemente, tanto Guillermo Lohmann Villena y María Justina Sarabia Viejo, como Carmen Ruigómez Gómez. volvieran a publicarlas..$^{22}$ Se puede decir que, globalmente, el interés suscitado por los virreyes ha sido más intenso y, por consiguiente, la historiografía sobre estos personajes más completa que la dedicada a los oidores, salvo escasas excepciones como, por ejemplo, la de Alonso de Zorita en Nueva España. ${ }^{23}$ Ahora bien, aunque don Francisco de Toledo no se refirió en ningún momento a las instrucciones de Tomás López Medel en sus ordenanzas para defensores de 1575, ¿es posible que las conociera y que se inspirara en ellas para redactar las propias?

A este propósito, cabe recordar algunas perspicaces observaciones de Lohmann Villena. Sin negar «la capacidad de observación» ni el «genio decisorio» de que estuviera dotado ese virrey, el investigador duda de que poco después de llegar al Perú éste ya «se hallase en aptitud de tener a punto y expedito para plasmar el fruto de sus experiencias en los copiosos textos legislativos, muchos de ellos extensos, de elevado tecnicismo y rigurosamente metodizados, que promulgara». ${ }^{24}$ De ahí la necesidad de «escudriñar las recónditas fuentes de las [ordenanzas] y esforzarse por identificar a quienes con sus proyectos ya elaborados facilitaron la tarea del virrey, acelerando su acción legislativa». ${ }^{25}$ En su indagación al respecto, Lohmann Villena señala las obras del licenciado Polo de Ondegardo, de los oidores de Lima y La Plata, González de Cuenca y Matienzo, y, finalmente, las del marqués de Cañete y el conde de Nieva. ${ }^{26}$ ¿Se puede, con alguna legitimidad, incluir las instrucciones para defensores de indios del oidor Tomás López Medel en esa lista?

El camino seguido por el virrey Francisco de Toledo en la elaboración de la legislación sobre los defensores de indios empezó en octubre de 1572 cuando promulgó en Checacupe ordenanzas para jueces de naturales. ${ }^{27}$

22 Ordenanzas sobre el defensor general de los indios de don Francisco de Toledo, Arequipa, 10 de septiembre de 1575, en Toledo, 1929, 281-284, en Francisco de Toledo, 1989, II, 101-112 y en Ruigómez Gómez, 1988, 189-197.

23 Vigil, 1987.

24 Francisco de Toledo, 1986, I, XXVI.

25 Ibidem, XXVII.

26 Ibidem, XXVIII-XXXIII.

27 Ordenanzas para jueces de naturales, Checacupe, 25 de octubre de 1572, Ibidem, 223-230. Parte de estas ordenanzas habían sido recogidas por Toledo en el título X de las ordenanzas de la ciudad del Cuzco y sus términos, dadas en Checacupe el 18 de octubre de ese mismo año, Ibidem, 179-182. 
Estipulaba que los jueces tendrían voz y voto en el gobierno local y facultad para determinar las causas indígenas y para ejecutarlas, siempre que las penas fuesen inferiores a dos marcos de plata. Para las condenaciones de mayor cuantía, deberían consultar al corregidor. ${ }^{28}$ Esas ordenanzas se distinguen, pues, de las instrucciones para defensores de Tomás López Medel por el poder judicial y ejecutivo de que gozaban los jueces, aspecto ausente en el texto del oidor. El citado virrey señalaba, además, que el precedente más inmediato de sus ordenanzas era un nombramiento de juez de naturales, otorgado por el Cabildo de la ciudad del Cuzco y sancionado por su predecesor, el virrey conde de Nieva, en $1563 .{ }^{29}$

En realidad, es en las ordenanzas para jueces de naturales, dictadas por Toledo en La Plata en 1574, donde mejor se percibe la influencia que pudieron tener las instrucciones de Tomás López Medel en las disposiciones del virrey del Perú. ${ }^{30}$ En el primer capítulo, en efecto, el gobernante reconocía que sus ordenanzas eran fruto no sólo de las «resultas de la visita general» y de sus observaciones «por vista de ojos en las chancillerías de los Reyes y esta ciudad de La Plata», sino también de las «informaciones que he tenido particulares, así de las provisiones que hallé en el valle de Jauja, como de las que tengo relación haberse proveído en todo el Reino», entre las cuales muy bien pudieron encontrarse las instrucciones para defensores de indios dictadas por el oidor Tomás López Medel para la audiencia del Nuevo Reino de Granada en 1557. ${ }^{31}$

En la parte introductoria del documento Francisco de Toledo justificaba sus medidas utilizando una serie de ideas muy afines con las del López Medel. Como el oidor, el virrey insistía en que la situación de desventaja cultural y socioeconómica sufrida por los indígenas en la sociedad colonial exigía que éstos gozaran de una protección especial en el sistema de justicia de la monarquía. También hacía suyas las ideas de que, sin los naturales, los reinos americanos no podían funcionar y que, siendo imprescindible el trato entre las repúblicas india y española, las relaciones entre ambas debían ser justas y equitativas. ${ }^{32}$ Dado el interés intrínseco del párrafo referido y sus afinidades con el pensamiento político de Tomás López Medel, nos parece conveniente reproducirlo aquí:

\footnotetext{
28 Ibidem, 225.

29 Idem.

30 Instrucción de los jueces de naturales, La Plata, 20 de diciembre de 1574, Ibidem, 461-486.

31 Ibidem, 482.

32 Sobre el pensamiento político del oidor Tomás López Medel, véase Ares Queija, 1993.
} 
[...] estamos obligados a acudir y favorecer a la parte más flaca que es la de los naturales, pues sin ellos la república quedaría sin fuerza y sin las partes necesarias para su conservación, de manera que la justicia sea común a ellos y a los españoles, haciendo de todos una república, proveyéndola de manera que todos vivan justificadamente y con igualdad y tengan entre sí comercio y trato, porque si lo contrario se hiciere, acostándonos a cualquiera de las partes con alguna violencia, tengo por averiguado que los unos y los otros no se gobernarían ni podrían sustentar como conviene para su aumento y perpetuidad..$^{33}$

Del mismo modo, Toledo mandaba revocar a todos «los defensores, abogados y procuradores de los indios que había en todas las audiencias, ciudades y villas de este reino» para evitar los abusos que éstos solían cometer contra los naturales, cobrándoles, por ejemplo, excesivos estipendios. ${ }^{34}$ Pero, consideraba justo que los indios pudieran ocurrir ante un profesional «quien les ayude y favorezca», «así en negocios que toquen a justicia como a gobierno». ${ }^{35}$ De ahí que el virrey volviera a usar la idea de Tomás López Medel, según la cual el defensor debía ser un oficial asalariado que se encargara gratuitamente de los asuntos indígenas. La medida aportaba, pues, una solución a las preocupaciones del Consejo de Indias acerca de la corrupción de los letrados que varias reales cédulas habían intentado atajar en los años anteriores. ${ }^{36}$ En las instrucciones de 1572, Francisco de Toledo explicaba, en efecto, que obedecía al «nuevo mandato» que le había confiado la corona para que «se eviten los pleitos entre los dichos naturales y no sean vejados ni molestados con costas saliendo de sus tierras y andando por las Audiencias perdidos como hasta aquí han hecho». ${ }^{37}$

Las ordenanzas de 1575 deben considerarse, por tanto, como la culminación de un proceso de definición legal del cargo de defensor de indios que hunde sus raíces en experimentos anteriores y a los que el citado gobernante dio una forma más acabada. Es probable que, sin las instrucciones de Tomás López Medel y sin otros textos de esta índole aún desconocidos, la obra legislativa del «supremo organizador del Perú» no fuera tan fructífera

33 Instrucción de los jueces de naturales, La Plata, 20 de diciembre de 1574, en Francisco de Toledo, 1986, I, 461.

34 Ibidem, 483.

35 Ibidem, 484.

36 Véase, por ejemplo, la real cédula a los oidores de la Audiencia de Nueva Galicia para que guarden con los indios el arancel de esos reinos en el llevar de los derechos sin multiplicación ninguna y que a los pobres no se les cobren derechos, Valladolid, 5 de julio de 1555, Encinas, 1945, IV, 357.

37 Ordenanzas para jueces de naturales, Checacupe, 25 de octubre de 1572, en Francisco de Toledo, 1986, I, 225. 
en aquel terreno. No obstante, también es cierto que el virrey Toledo aportó importantes precisiones al texto de López Medel, siendo sus mayores logros el haber establecido una estricta jerarquía entre los distintos tipos de defensores y definido la naturaleza de las relaciones que estos oficiales debían mantener con las demás instancias de poder.

Para Francisco de Toledo, en efecto, mientras que los jueces de naturales actuaban en relación con los repartimientos y averiguaban las querellas de los indios «breve y sumariamente», los defensores de las reales audiencias y de las ciudades tenían que seguir sus pleitos ante esos máximos tribunales. Finalmente, el defensor general era responsable de que los defensores subordinados cumplieran con su cometido y debía estar próximo al virrey para que, informado de sus demandas de los indios, las pidiese ante él. ${ }^{38}$ Trataba «los negocios graves que tocan al Gobierno que no pueden determinarse ante los corregidores y Reales Audiencias» ${ }^{39}$ En caso de que algún asunto tuviera que ser presentado ante el Consejo de Indias, también debía cuidar que se remitiese en la primera flota que saliera para la metrópoli. ${ }^{40}$ Se puede considerar, por consiguiente, que las ordenanzas del virrey Toledo mejoraron el grado de articulación entre los distintos niveles territoriales.

Lohmann Villena señala que «las pruebas de la recepción de las ordenanzas [de Toledo] por la legislación promulgada por la corona o por las autoridades virreinales [...] son abrumadoras».41 Las ordenanzas para defensores de indios no escapan a esa regla: gracias a ellas, este cargo de defensor adquirió una mayor proyección por el continente de la que pudo gozar con las instrucciones de Tomás López Medel, marcando así un paso decisivo hacia el asentamiento definitivo y la institucionalización del cargo en América. Por real cédula de 1589, en efecto, el Consejo de Indias mandó al virrey marqués de Cañete que diese a todos los defensores «las instrucciones y ordenanzas que hizo el virrey don Francisco de Toledo para que las guarden y cumplan». ${ }^{42} \mathrm{El}$ texto, además de ser recopilado por Diego de Encinas en su Cedulario de finales del siglo XVI, también fue recorda-

38 Ordenanzas para defensores de indios del virrey don Francisco de Toledo, Arequipa, 1575, en Ruigómez Gómez, 1988, 189 y 191.

39 Ibidem, 191, 193 у 195.

40 Ibidem, 191.

41 Francisco de Toledo, 1986, I, XL.

42 Real cédula mandando al virrey del Perú, que provea los oficios de protectores de indios que solía haber en personas de edad, aprobación y cristiandad para que defiendan sus causas, Madrid, 10 de enero de 1589, en Encinas, 1945, IV, 334-335. 
do en la Recopilación de Leyes de los Reynos de Indias de $1680 .{ }^{43}$ Todavía en el siglo XVIII la Corona seguía exaltando las excelencias de lo dispuesto por Toledo sobre los defensores de indios. ${ }^{44}$

\section{Las funciones del defensor de indios}

Hemos agrupado esas funciones, definidas por el oidor Tomás López Medel en sus instrucciones, en tres ejes principales: el asesoramiento jurídico gratuito a los indígenas, la difusión de la información entre los indios y la corona y, finalmente, la regulación de las relaciones interétnicas.

\section{Representar a los indígenas en sus pleitos}

Dada la situación de desventaja en que se encontraban los naturales a la hora de presentar sus quejas en el sistema jurídico colonial, no es de extrañar que el primer apartado de las instrucciones de Tomás López Medel estuviera dedicado a la función representativa de este oficial. El defensor actuaría como un abogado especializado en causas indígenas, encargado de presentar y seguir sus pleitos ante los tribunales de las gobernaciones o de las reales audiencias. Recibiría, promovería y seguiría sus querellas ante las autoridades competentes «hasta la final conclusión de ellas, por manera que los dichos naturales sean desagraviados y alcancen justicia y no la pierdan por no tener quien la siga por ellos». ${ }^{45}$ La última parte del apartado dejaba claro que el ocupante de este cargo debía suplir las deficiencias ocasionadas por la falta de abogados dispuestos a defender a los indios de forma desinteresada y eficaz.

Según Tomás López Medel, gracias a los defensores, los indígenas tendrían quien los representara y así ya no perderían tiempo ni se gastarían el dinero en promover sus causas ante las autoridades coloniales. A pesar del estudio de Lohmann Villena sobre la trayectoria del procurador de causas especializado en litigios indígenas, el licenciado Francisco Falcón,

43 Que en el Perú se den las instrucciones, conforme a las ordenanzas del virrey Don Francisco de Toledo, en Recopilación de Leyes de los Reynos de Indias, lib. VI, tít. VI, ley 2.

44 Francisco de Toledo, 1986, I, XLIV.

45 AGI, Justicia, 251, 644-650, instrucciones para defensores de Tomás López Medel, Mérida, 21 de diciembre de 1553 . 
todavía siguen siendo poco conocidos estos letrados que representaban jurídicamente a los naturales en sus pleitos ante las audiencias americanas. Renzo Honores, sin embargo, ha llamado la atención sobre la necesidad de analizar «cómo los señores indígenas se sirvieron del patrocinio privado de abogados y procuradores de causas para iniciar y llevar a cabo sus litigios» e insiste en cuán fructífero resultaría un análisis de estos profesionales. ${ }^{46}$ Recientemente, Ethelia Ruiz Medrano ha demostrado cómo en la segunda mitad del siglo XVI los procuradores Agustín Pinto y Álvaro Ruiz se especializaron en las causas indígenas presentadas ante la Real Audiencia de México. ${ }^{47}$ Medidas como las tomadas por Tomás López Medel impulsaron, pues, el paso progresivo de una representación jurídica privada a otra asumida por estos defensores oficiales nombrados por la corona.

En sus instrucciones, el oidor también insistía en que los defensores debían garantizar los derechos de los indios del común en caso de que fueran maltratados por sus caciques. Este importante elemento indica que dicho funcionario protegería a los indígenas no sólo de los abusos de los españoles, sino también de los de sus propios gobernantes. Se trataba, por consiguiente, de que todos los indios tuvieran acceso a la justicia colonial y de que el defensor representara tanto a los caciques, como a los indios del común. Y es que, hasta esa fecha, solían ser los gobernantes indígenas quienes más se beneficiaban del sistema de justicia colonial porque disfrutaban, por lo general, de recursos financieros superiores, estaban mejor formados y tenían más trato con los españoles.

El oidor ponía, pues, de manifiesto su voluntad de que todos los vasallos de la corona alcanzaran una representación jurídica, de manera que se pudieran regular las relaciones políticas y económicas entre indios en el seno de sus repúblicas. Así, el quinto capítulo de las instrucciones de Yucatán establecía que si los caciques hubiesen cobrado excesivos tributos a sus indios, el defensor debía pedir su devolución. ${ }^{48}$ En las instrucciones de Santa Fe, Tomás López Medel llegó a dedicar un capítulo especial al control de los caciques. Y es que se debe advertir que dichas disposiciones se insertaban en un contexto general de crítica al cacicazgo por los abusos que esos gobernantes solían perpetrar en contra de sus sujetos. En las ordenanzas para pueblos de indios de Yucatán de 1553 se instaba, por ejemplo,

\footnotetext{
46 Lohmann Villena, 1970 y Honores, 2003.

47 Ruiz Medrano, 2010, 48-61.

48 AGI, Justicia, 251, 644-650, instrucciones para defensores de Tomás López Medel, Mérida, 21 de diciembre de 1553 .
} 
a los caciques a que fueran como padres para sus repúblicas y se les prohibían expresamente algunas costumbres consideradas como abusivas. ${ }^{49}$

\section{Difundir la información entre los naturales y la corona}

Como abogado especializado en negocios indígenas, el defensor no tenía ningún poder ejecutivo ni legislativo, al contrario de lo que había pasado con los protectores eclesiásticos o con los jueces de naturales, los cuales tenían facultad para castigar los delitos menores que afectaran a los indígenas. ${ }^{50} \mathrm{El}$ defensor civil sólo podía pedir a las autoridades que fuera aplicada la legislación favorable a los indios, como bien lo asentaba Tomás López Medel en el undécimo capítulo de las instrucciones de Santa Fe. Recordaba a los defensores que

generalmente, se [les] da[ba] por instrucción que procur[aran] la ejecución y efecto de todas las leyes, cédulas y provisiones de S. M. y de otros cualesquier mandamientos de otros cualesquier jueces que haya o se hayan dado para el bien y aumento y defensa de los dichos indios..$^{51}$

El oidor no pretendía crear una jurisdicción especial para los asuntos indígenas, pues hubiera podido generar numerosos conflictos con los demás órganos de gobierno, como había ocurrido, por ejemplo, durante la etapa eclesiástica de la protectoría. El hecho de que Tomás López Medel presenciara las querellas que se desataron en la real Audiencia de Guatemala entre las autoridades eclesiásticas y civiles acerca del control de la población indígena tuvo que empujarlo a tomar esta medida. ${ }^{52}$ Según este oidor, todas las autoridades indianas debían de procurar la conservación y aumento de los naturales y el defensor sólo tenía una responsabilidad especial y exclusiva en esta misión colectiva.

La ausencia de poder legislativo y ejecutivo del defensor hizo que la función informativa se convirtiera en un aspecto crucial en el mandato del defensor de indios. La cuestión de la difusión de la información, tanto de la metrópoli a América, como en el sentido inverso e, incluso, dentro de

\footnotetext{
49 Ordenanzas para pueblos de indios, Mérida, 1552, en Ares Queija, 1993, 384.

50 Sobre este aspecto de la protectoría eclesiástica, Friede, 1956, 643-655. 390.

51 Instrucciones para defensores de Tomás López Medel, Santa Fe, s.f., en Ares Queija, 1993,

52 Acerca de esas querellas y de la posición del oidor, ver Ares Queija, 1993, 29-31.
} 
aquel continente, entre las distintas instancias de poder, siempre constituyó una de las preocupaciones mayores de Tomás López Medel. ${ }^{53}$ Ares Queija explica que, para el oidor, el control de la información era «un instrumento primordial para poder gobernar bien aquellas tierras tan alejadas del centro de poder», de ahí que éste considerara que sólo podían «emitirse desde la metrópoli las leyes y disposiciones de gobierno adecuadas» si se contaba «con una información correcta y fiable, desprovista de particularismos personales o de grupo y elaborada colectivamente por los representantes del poder real, las autoridades eclesiásticas y otras personas destacadas por su conocimiento del medio». ${ }^{54}$ Como consecuencia, se puede argumentar que la misión informativa del defensor ideada por Tomás López Medel formaba parte de un proyecto global destinado a mejorar la calidad y la autenticidad de la información acerca de las condiciones de vida de los naturales que llegaba a las reales audiencias y al Consejo de Indias.

Para el oidor, en efecto, el envío de informes sobre la situación indígena debía impulsar tanto el cumplimiento de las leyes existentes, como la promulgación de nuevas cédulas cuando éstas hicieran falta. Así, el segundo apartado de ambas instrucciones estaba dedicado a la relación anual sobre el trato dado a los naturales que el defensor debía enviar a la Audiencia para que sus miembros proveyeran al respecto conforme a derecho:

[...] os informaréis y sabréis en cada un año, una vez o dos o las que fueren menester, qué malos tratamientos, robos, fuerzas y otros agravios cualesquier han recibido los dichos naturales [...], la cual dicha información enviaréis a la dicha Real Audiencia por año nuevo de cada un año para que en ella se sepa quién trata bien y mal los dichos naturales y qué daño les hacen y se provea sobre ello lo que convenga. ${ }^{55}$

Con el fin de que el defensor pudiera conseguir los datos necesarios para la redacción de aquellos informes, se le daba licencia para desplazarse libremente por los pueblos de indios o para mandar llamar a los naturales. ${ }^{56}$

En la versión de Santa Fe el oidor también insistía en el papel activo que el defensor tenía que desempeñar en el acopio de la información con una fórmula más genérica, estipulando que «de vuestro oficio y por todas

53 Sobre el papel de la información en el gobierno de América, véase Bustamante, 2000.

54 Ares Queija, 1993, 62. La autora cita la carta de Tomás López a los reyes de Bohemia, Guatemala, 25 de marzo de 1551, Ares Queija, 1993, 299 y 87. 1553.

55 AGI, Justicia, 251, 644-650, instrucciones para defensores, Mérida, 21 de diciembre de

56 Idem. 
las vías, aunque los dichos indios no se vengan a quejar, os informaréis qué agravios, daños e injurias hayan recibido, para que pidáis ante la justicia como es dicho». Tomás López Medel explicaba que se otorgaba tal atribución al defensor «porque muchas veces, por miedos y por amenazas y por ser los dichos indios y los demás encogidos y medrosos, no osan ni saben pedir su justicia». ${ }^{57}$ El letrado aludía, pues, al concepto jurídico de miserable y lo vinculaba tanto a circunstancias externas, es decir, la coerción ejercida sobre los indígenas, como a aspectos culturales referidos a la falta de conocimiento del sistema de justicia hispano y el temperamento humilde del indio. Es importante subrayar que, para justificar sus medidas, Tomás López Medel no se refería a una supuesta inferioridad innata del indígena, argumento que aparecería en años siguientes, sino a desigualdades de tipo cultural y social. ${ }^{58}$

\section{La regulación de las relaciones interétnicas}

Gracias al conocimiento de las leyes protectoras de los indios y al de la situación real en la que éstos vivían, el defensor debía cumplir con el objetivo principal planteado por López Medel en las instrucciones, el de controlar las relaciones interétnicas. Como advirtió Ares Queija, el oidor pensaba que las repúblicas india y española eran como «carne y hueso», pues la conversación y el trato entre ambas eran inevitables ${ }^{59}$ En el contexto de tensiones provocadas por la promulgación de las Leyes Nuevas en Nueva España, fray Juan de Zumárraga, fray Martín de Hojacastro y fray Francisco del Soto ya habían utilizado la metáfora corporal para referirse a la sociedad colonial. En una carta de 1543 los religiosos exponían al emperador que, para conservar y aumentar sus reinos, se requería «grande atadura y vínculo de amor» entre españoles e indios, ya que eran como «huesos y carne» ${ }^{60} \mathrm{El}$ rey, como cabeza de este cuerpo, debía tratar a ambas partes con justicia y equidad, es decir, recompensar a los españoles conforme a sus méritos y tener para los naturales «la misma afección de verdade-

57 Instrucciones para defensores, Santa Fe, s.f., en Ares Queija, 1993, 388.

58 Sobre el concepto jurídico de miserable que se les aplicó a los indios en la América colonial, véanse Castañeda Delgado, 1971; Assadourian, 1990 y Cunill, en prensa.

59 Ares Queija, 1993, 119. Sobre el origen y el significado de la metáfora del cuerpo en la teoría política de la época, véase Lempérière, 2004, 26-29.

60 Los franciscanos fray Juan de Zumárraga, fray Martín de Hojacastro y fray Francisco del Soto al emperador, 4 de octubre de 1543, carta citada por Traslosheros, 2004, 161-163. 
ro señor y padre que a los españoles, procurando de saber cómo les va y cómo son tratados». Sólo así «cada y cuando que se sintiesen agraviados, antes acudirán al amparo y protección de V. M. que a las armas» ${ }^{61}$ Destaca, una vez más, el papel que los pensadores de aquella época otorgaban a la justicia para el adecuado funcionamiento y mantenimiento de la monarquía hispana. ${ }^{62}$

Para Tomás López Medel, si se quería que las interacciones entre indios y españoles resultaran beneficiosas para todos, tenían que realizarse conforme al derecho. Pero, si bien en un principio estaba convencido de que en América «no falta[ba] justicia que vuelve por [los indios] ya que haya algún descomedido», ${ }^{63}$ con el paso del tiempo se deterioró la idea que tenía el oidor tanto del colonizador, como de las autoridades indianas. De ahí su creciente énfasis en la necesidad de vigilar que los españoles no perjudicaran a los indios. ${ }^{64}$ Según este planteamiento, el papel de mediación del defensor de indios resultaba capital. En consecuencia, el tercer apartado de las instrucciones de Yucatán estipulaba que el defensor debía presenciar todos los contratos entre indios y españoles, tanto en el terreno comercial como en el laboral, para que se hicieran «como viéredes que más conviene al bien y pro de los dichos naturales por manera que no sean engañados ni dañificados». ${ }^{65}$ Todos los «conciertos» realizados sin la presencia del defensor se considerarían nulos y los indígenas, por tanto, no tendrían obligación de cumplirlos. El cuarto apartado estaba más específicamente dedicado a la compra-venta de material destinado a la comunidad o a las iglesias. En estas operaciones también se exigía la presencia del defensor, no sólo para evitar que se cobrara a los indios un precio excesivo, sino también para asegurarse de que «sean cosas que haya menester y no cosas superfluas y que las puedan pagar buenamente y sin vejación» y si algunos artículos fueran adquiridos de otra manera, los naturales no deberían pagarlos. ${ }^{66}$

61 Ibidem, 163.

62 Maravall, 1972, 2 vols.; Martiré, 2005 y Zorraquín Becú, 1948.

63 Tomás López Medel a los reyes de Bohemia, Guatemala, 25 de marzo de 1551, en Ares Queija, 1993, 308.

64 Acerca de la nueva actitud del oidor frente a la realidad colonial, ver Ibidem, 134-136.

65 AGI, Justicia, 251, 644-650, instrucciones para defensores, Mérida, 21 de diciembre de 1553.

66 Idem. Estos comentarios sugieren la existencia de una demanda de artículos religiosos por parte de los indios para adornar sus iglesias en aquella época de construcción de los pueblos conforme al modelo hispano, tema que merecería la pena profundizar en otra ocasión. 
En las instrucciones de Yucatán, los apartados 5 y 8 especificaban la misión del defensor en el ámbito de las relaciones laborales. El oidor recordaba que los encomenderos no debían cobrar tributos excesivos a sus indios y, si ocurriera, el defensor tenía que procurar que se les devolviera «lo que les fuere mal llevado». Esos oficiales también vigilarían que las tasaciones fueran justas y actualizadas conforme al número de vecinos de cada comunidad indígena. Por otro lado, el defensor procuraría controlar que los españoles pagaran a los indios que trabajaban para ellos su jornal. Finalmente, Tomás López Medel no se olvidaba de los naborías que residían en las ciudades españolas: en el capítulo 11 mandaba que fueran visitados anualmente por las autoridades en presencia del defensor.

Al defensor se le encargaba controlar las relaciones de los indios no sólo con los vecinos españoles, sino también con las autoridades indianas. En efecto, en el segundo apartado de las instrucciones de Yucatán, se estipulaba que él debía informar a la real audiencia acerca de las sanciones tomadas contra los infractores de las leyes protectoras «para que se vea también cómo las justicias de estas dichas provincias castigan los malos tratamientos y agravios que a los naturales de ellas se hacen». Con el paso del tiempo, Tomás López Medel pondría más énfasis en este aspecto, dado que pensaba que los defensores debían participar en los juicios de residencia que se tomaban a las autoridades como representantes de los intereses indígenas. Así, en su carta al rey del 20 de diciembre de 1557, el oidor recomendaba que los jueces «mandasen pregonar las residencias en los pueblos de indios» y que se nombrara a un defensor «para que [los naturales] pidiesen los disfavores que han recibido de los jueces y las cédulas y provisiones que han disimulado y las malas tasas que han hecho». ${ }^{67}$

\section{Consideraciones finales}

Las instrucciones para defensores de indios del oidor Tomás López Medel ilustran la «notable importancia [que] tiene la labor legislativa de los oidores enviados como visitadores», al constituir, junto con las leyes promulgadas por virreyes, audiencias, gobernadores, cabildos y gremios, el origen de lo que Sánchez Bella denomina, siguiendo a García-Gallo, el «derecho indiano criollo» para distinguirlo de la legislación creada en la

67 Tomás López Medel al rey, Santa Fe, 20 de diciembre de 1557, en Ares Queija, 1993, 334. 
metrópoli. ${ }^{68}$ Las instrucciones daban una forma más acabada a una propuesta contenida en un capítulo de carta real de 1551, en la que se ordenaba a la audiencia de Nueva España que proveyera a una persona que «ayude y favorezca [a los indios] y solicite sus causas por manera que, por falta de ella, no reciban agravio y dejen de alcanzar justicia». ${ }^{69}$ El texto de López Medel se sustentaba en un excelente conocimiento de la realidad americana y una profunda reflexión sobre la sociedad colonial por parte del oidor.

Se puede considerar que la figura del defensor de indios se insertaba plenamente en la teoría de dos repúblicas, española e indígena, cuyas interacciones debían ser controladas por un representante de la corona. Se trataba, en efecto, de representar a los naturales en sus pleitos y de regular así las relaciones interétnicas, de forma que las tensiones vividas en la sociedad colonial se desplazaran hacia el ámbito jurídico, al ofrecer el litigio la posibilidad de obtener satisfacción o, al menos, de expresar las vejaciones sufridas. Owensby considera, en efecto, que la ley «representa un terreno de contestación, un sitio donde la gente del común puede expresar sus problemas e, incluso, ganar sus causas frente a sus superiores». ${ }^{70} \mathrm{Al}$ no tener el defensor poder legislativo ni ejecutivo, el conocimiento de las leyes protectoras de los indios y la comunicación con las autoridades adecuadas se convertían en la principal arma de este oficial.

68 Sánchez Bella, 1995, 72.

69 Borah, 1985, 74-75. El documento original fue publicado en los cedularios de Puga y de Encinas. Capítulo de carta real dirigida a la audiencia de Nueva España sobre que envíe su parecer acerca de que los indios tengan un solicitador, Valladolid, 7 de julio de 1551, Puga, 1945, II, 121 y Encinas, 1945, IV, 375-377.

70 Owensby, 2005, 39-80. 


\section{Apéndice Documental}

Nombramiento de defensor de los naturales en Hernando Muñoz Zapata e instrucciones del lic. Tomás López Medel, Mérida, 21 de diciembre de 1553. AGI, Justicia, 251, 644-650.

El lic. Alonso Ortiz Delgata, justicia mayor por S. M. en estas provincias y gobernación de Yucatán, Tabasco y Cozumel, por cuanto el lic. Tomás López, oidor de la Real Audiencia de los Confines, al tiempo que estuvo en estas dichas provincias y gobernación nombró defensor de los pueblos y naturales de los términos de esta ciudad de Mérida de las dichas provincias según parece y consta por el dicho nombramiento e instrucción que para lo usar y ejercer le dio que mande poner de aquí adelante:

Yo, el lic. Tomás López, oidor por S. M. en su real Audiencia de los Confines y su justicia mayor en estas provincias de Yucatán, Cozumel y Tabasco, por cuanto en la ciudad de Mérida de la dicha provincia de Yucatán y Cozumel conviene y es necesario que haya un defensor de los naturales de los pueblos de los términos de la dicha ciudad y de los demás indios y naborías que en la dicha ciudad de Mérida y sus términos residen, porque tengan quien hable y vuelva por ellos e intime a las justicias porque no perezcan y sean castigados los que mal y daño les hicieren y también se les pague lo que se les debiere y para que en los contratos y otros conciertos que hubieren de hacer con los españoles en cualesquier cosas que quisieren, porque los dichos naturales no sean agraviados ni engañados o pasen y se hagan ante defensor y para otras cosas que de yuso irán declaradas convenientes a los dichos naturales, por ende, confiando de vos, Hernando Muñoz Zapata, vecino de la dicha ciudad, que sois persona que bien y fielmente usaréis el dicho cargo por la presente vos nombro por defensor de todos los dichos naturales para que lo uséis y ejercéis hasta tanto que por S. M. y la dicha real Audiencia otra cosa sobre ello provea y mande y para que sepáis cómo y de qué manera lo debéis usar y lo que, como tal defensor, debéis hacer, guardaréis en ellos la intrucción y forma siguiente:

1. Que habiendo algunos de los dichos naturales y naborías querellosos de algunos españoles u otras personas que los hayan maltratado o hecho algunas fuerzas o robos y otros algunos agravios, molestias e injurias, recibiréis sus querellas y por vos o por vuestro procurador que para ello podáis nombrar las promoveréis ante la justicia de la dicha ciudad y seguiréis ante las dichas justicias las dichas querellas y otros cualesquier pleitos civiles que les toquen hasta la final conclusión 
de ellas por manera que los dichos naturales sean desagraviados y alcancen justicia y no la pierdan por no tener quien la siga por ellos.

2. Iten os informaréis y sabréis en cada un año una vez o dos o las que fueren menester qué malos tratamientos, robos, fuerzas y otros agravios cualesquier han recibido los dichos naturales y se les han hecho y qué personas los hicieron, la cual dicha información enviaréis a la dicha real Audiencia por año nuevo de cada un año para que en ella se sepa quién trata bien y mal los dichos naturales y qué daño les hacen y se provea sobre ello lo que convenga, lo cual haréis y cumpliréis así con toda diligencia, no obstante que los dichos malos tratamientos sean castigados por la justicia y para que se vea también cómo las justicias de estas dichas provincias castigan los malos tratamientos y agravios que a los naturales de ellas se hacen y para que si no estuvieren bien castigados se provea cómo se castiguen conforme a derecho y los dichos naturales queden desagraviados so pena que si así no lo hiciéredes se castigará en vuestra persona y bienes la culpa que en ellos tuviéredes.

3. Iten que los conciertos y contratos que algunos de los dichos naturales y naborías quisieren hacer con algunos españoles así para servirles como para hacerles algunas obras y para otras cualesquier cosas que ellos quisieren concertarse o comprando y vendiendo alguno o en otra manera, que las tales contrataciones y conciertos pasen ante vos el dicho defensor y sin vos no se puedan hacer ni hagan y los hagáis y concertéis como viéredes que más conviene al bien e pro de los dichos naturales por manera que no sean engañados ni dañificados y el contrato que de otra manera se hiciere con algun indio no valga ni el tal indio ni indios sean obligados a ellos y por todas vías procuréis que los dichos indios sean pagados de lo que hicieren y trabajaren y por otra cualquier vía que se les lleva.

4. Iten que si los dichos naturales hubieren menester algunas cosas para sus iglesias y pueblos y común que no se les pueda vender sin que vos estéis presente y lo concertéis para que no se les venda cosa por más precio de lo que valen y ésto precediendo licencia del prelado o de quien tuviere sus veces y miraréis que lo que compraren sean cosas que haya menester y no cosas superfluas y que las puedan pagar buenamente y sin vejación y en todo haréis de manera que no sean los dichos indios agraviados en lo que compraren y lo que de otra manera se les compraren no valgan ni sean obligados a lo pagar.

5. Iten procuraréis que a los dichos naturales no se les lleven tributos demasiados por sus caciques y principales ni por sus encomenderos ni por otra persona ni se les pongan otras imposiciones e informaréis de los macehuales si el cacique y principales o encomendero u otra persona les ha llevado alguno demasiado y que no deban so color que es para su iglesia ni por otros achaques algunos y lo que les fuere mal llevado se lo hagáis volver. 
6. Iten procuraréis de inquirir y saber si algunos macehuales se huyen de sus pueblos para otros y los haréis volver a sus pueblos y asientos y acerca de ésto haréis guardar las ordenanzas que sobre ello yo dejo hecha como en ellas se contiene.

7. Iten que os informéis e procuréis por todas vías las borracheras, idolatrías y hechicerías y otras cosas semejantes que retardan e impiden la conversión de los dichos naturales y de ello daréis aviso a la justicia para que lo remedien y castiguen a los indios que lo hicieren y caciques que lo consintieren, de manera que es todo y por todo hagáis que entre los dichos naturales se guarde lo que yo dejo ordenado en este caso para que no haya borracheras.

8. Iten que vos el dicho defensor seáis obligado a inquirir e informaros por todas vías de los naturales de esta dicha ciudad de Mérida y sus términos, qué pueblos de ella están agraviados en las tasas de los tributos que han de dar y de lo demás y siendo así que están agraviados y por no estar bien informados los que los tasaron y por haberse muerto los indios de los tales pueblos y haber venido en disminución y por otras razones, seáis obligado a pedir y pidáis a la dicha real Audiencia que en su poder tuviere que desagravie a los tales pueblos que estuvieren agraviados en la tasa y provea en ello con justicia y generalmente tengáis especial ciudado de ser y procurar todo bien espiritual y temporal de los dichos naturales y desviar todo mal y daño, que no se les tome lo que tienen y les sea pagado su jornal y lo demás y pedir sobre ello cumplimiento de justicia y sobre todo lo cual se os encarga la conciencia.

9. Iten si para informaros y saber más cumplidamente las cosas susodichas y otras semejantes fuere necesario ir a los pueblos de los naturales y enviarlos a llamar lo podáis hacer cuando os pareciere y para hacer la general información e inquisición que en cada un año habéis de hacer para enviar a la dicha real Audiencia así de los males tratamientos como de otras cosas llevaréis un escribano ante quien pasen o la haréis por vos.

10. Iten que vos el dicho defensor seáis obligado a tener y tengáis dos traslados, uno de las ordenanzas y capítulos que yo dejo para el gobierno de los naturales de esta dicha provincia y otro de las que dejo para los encomenderos de ellas, cómo se han de haber con sus indios para que vos, el dicho defensor, por ellas veáis quién las cumple o no y lo que son obligados de hacer los unos y los otros para que tengáis ciudado de pedir ante la justicia el cumplimiento y ejecución de ellas.

11. Iten mando que vos, el dicho defensor, seáis obligados en cado un año una vez de pedir a las justicias de esta dicha ciudad que, conforme a una cédula de S. M. que cerca de ésto habla, discurran por las naborías de esta dicha ciudad y las visite y sepa cómo son tratados y pagados de sus jornales para que los que no fue- 
ren bien tratados y pagados se les haga cumplimiento de justicia y sean desagraviados conforme a las ordenanzas que yo dejo, la cual visita mando que se haga juntamente con vos, el dicho defensor.

12. Iten que vos, el dicho defensor, seáis obligado en cada un año a inquirir y saber en esta dicha provincia o en alguna parte de ellas si ha habido o hay esterilidad en común de todos los frutos o en particular de algunos, por manera que los naturales de esta dicha provincia no hayan cogido frutos de que pagar sus tributos y pidáis a las justicias de esta ciudad que, conforme a derecho y a una particular provisión de S. M. dada para el favor de los naturales de estas partes sean reservados de le pagar el tributo en aquel año en los frutos en que hubiere habido la tal esterilidad y ésto siendo tal la esterilidad que por derecho deban ser reservados de pagarlo y encargárseos la conciencia que los informéis bien y no déis lugar a malicias ni que los naturales de esta dicha provincia tomen achaques para no sembrar y fingir esterilidad por no pagar el tributo.

13. Iten conviene lo susodicho se guarde e cumpla por vos, el dicho Hernando Muñoz Zapata, vos mando que esto vos fuere notificado parezcáis ante mí a aceptar el dicho cargo y hacer el juramento y solemnidad que debéis hacer para lo usar so pena de privación de los indios que tenéis en encomienda y destierro perpetuo de esta provincia de Yucatán por cuanto así conviene al servicio de Dios y de S. M. y bien de los naturales so la cual dicha pena mando que ninguna persona vos ponga impedimento en el dicho cargo y que libremente vos lo dejen usar y ejecer so pena de 100 pesos de oro para la cámara de S. M. al que lo contrario hiciere y destierro perpetuo de esta provincia demás de la pena dicha.

14. Y porque en lo susodicho entendáis con todo ciudado y diligencia y por el trabajo que en ello habéis de tener, vos señalo de salario con el dicho cargo 100 pesos de oro de minas, los sesenta de la caja de S. M. y los cuarenta que los paguen los indios de esta provincia cuyo defensor sois en cada un año y se reparta entre ellos por uno de los del Cabildo de esta ciudad juntamente con el prelado de la Orden de San Francisco que entiende en la doctrina de los dichos naturales y mando a los oficiales de S. M. que vos den, libren y paguen los dichos sesenta pesos de oro cada año por los tercios de él y tomen vuestras cartas de pago con las cuales y con este mi mandamiento se les recibirán y pasarán en cuenta. Ésto hasta tanto que por S. M. o la dicha su real Audiencia sobre ello otra cosa se provea y mande. Hecho en la dicha ciudad de Mérida, a 21 de diciembre de 1553 años, el lic. Tomás López por mandado de su merced, Juan García de Madrid, escribano de S. M. 
TOMÁS LÓPEZ MEDEL Y SUS INSTRUCCIONES PARA DEFENSORES DE INDIOS

\section{Bibliografía}

Ares Queija, Berta: Visita de la gobernación de Popayán. Libro de tributos (15581559), Madrid, CSIC, 1989.

Ares Queija, Tomás López Medel. Trayectoria de un clérigo-oidor ante el Nuevo Mundo, Guadalajara, Institución Provincial de Cultura «Marqués de Santillana», 1993.

Assadourian, Carlos Sempat: «Fray Bartolomé de las Casas obispo: la condición miserable de las naciones indianas y el derecho de la Iglesia (un escrito de 1545)», Allpanchis, XII-35/36, El Cuzco, 1990, 29-104.

Bayle, Constantino: El protector de indios, Sevilla, CSIC, 1945.

Borah, Woodrow: El Juzgado General de Indios en la Nueva España, México, Fondo de Cultura Económica, 1985.

Bracamonte y Sosa, Pedro: La conquista inconclusa de Yucatán: los mayas de las montañas, 1560-1680, Mérida, CIESAS, 2001.

Bustamante, Jesús: «El conocimiento como necesidad de Estado: las encuestas oficiales sobre Nueva España durante el reinado de Carlos V», Revista de Indias, LX-218, Madrid, 2000, 33-57.

Castañeda Delgado, Paulino: «La condición miserable del indio y sus privilegios», Anuario de Estudios Americanos, XXVIII, Sevilla, 1971, 245-335.

Cunill, Caroline: «Los defensores de indios de Yucatán y el acceso de los mayas a la justicia colonial, 1540-1600», Tesis doctoral, Universidad de Toulouse IILe Mirail, 25 de febrero del 2011.

Cunill, «El indio miserable: nacimiento de la teoría legal en la América colonial del siglo XVI», Intercambio, VIII, Costa Rica, en prensa.

Dussel, Enrique D.: Les évêques hispano-américains Défenseurs et évangélisateurs de l'Indien (1504-1620), Wiesbaden, Franz Steiner Verlag G.M.B.H, 1970.

Encinas, Diego de: Cedulario Indiano, Madrid, Ediciones de Cultura Hispánica, 1945, 4 ts.

Farriss, Nancy: Los Mayas bajo el dominio colonial. La empresa colectiva de supervivencia, Madrid, Alianza Editorial, 1992.

Francisco de Toledo. Disposiciones gubernativas para el virreinato del Perú, Introducción de Guillermo Lohmann Villena y transcripción de María Justina Sarabia Viejo, I, 1569-1574 y II, 1575-1580, Sevilla, Escuela de Estudios Hispano-Americanos-Consejo Superior de Investigaciones Científicas-Monte de Piedad y Caja de Ahorros de Sevilla, 1986 y 1989.

Friede, Juan: «Los orígenes de la protectoría de indios en el Nuevo Reino de Granada (primera mitad del siglo XVI)», en Miscelánea de Estudios dedicados al Dr. Fernando Ortiz por sus discípulos, colegas y amigos, La Habana, Úcar García Guill, 1956, 643-655. 
Friede, Fuentes documentales para la historia del Nuevo Reino de Granada, Bogotá, Biblioteca Banco Popular, 1976.

García Bernal, Manuela Cristina: «García de Palacio y sus ordenanzas para Yucatán», Temas Americanistas, V, Sevilla, 1985, 8-14.

Germán Romero, Mario: Fray Juan de Barrios y la evangelización del Nuevo Reino de Granada, Bogotá, Editorial ABC/Academia Colombiana de Historia, 1960.

González Cicero, Stella María: Dos cartas del oidor Tomás López Medel, Guadalajara, Editorial Font/Documentación Histórica Mexicana, 1980.

Honores, Renzo: «La asistencia jurídica a los señores indígenas ante la Real Audiencia de Lima», Latin American Studies Association, Dallas, 27-29 de marzo de 2003, en línea (última consulta, el 7 de junio del 2010).

Lempérière, Annick : Entre Dieu et le roi, la république. México, XVI'me-XIX ème siècles, Paris, Les Belles Lettres, 2004.

Levillier, Roberto: Don Francisco de Toledo, supremo organizador del Perú: su vida, su obra (1515-1572), Madrid, Espasa-Calpe, 1935-1942, 3 vols.

Lohmann Villena, Guillermo: «El licenciado Francisco Falcón (1521-1587). Vida, escritos y actuación en el Perú de un procurador de los indios», Anuario de Estudios Americanos, XXVII, Sevilla, 1970, 131-194.

López Medel, Tomás: De los tres elementos. Tratado sobre la Naturaleza y el hombre del Nuevo Mundo, edición y estudio preliminar de Berta Ares Queija, Madrid, Alianza Editorial, 1990.

Maravall, José Antonio: Estado Moderno y mentalidad social (siglos XV a XVII), Madrid, Alianza Editorial, 1972, 2 vols.

Martiré, Eduardo: Las Audiencias y la administración de la justicia en las Indias, Madrid, Ediciones de la Universidad Autónoma de Madrid, 2005.

Owensby, Brian P.: «How Juan and Leonor Won Their Freedom: Litigation and Liberty in Seventeenth-Century Mexico», Hispanic American Historical Review, 85-1, Pittsburg, 2005, 39-80.

Puga, Vasco de: Provisiones, cédulas e instrucciones para el gobierno de la Nueva España, Madrid, Ediciones Cultura Hispánica, 1945.

Ruigómez Gómez, Carmen: Una política indigenista de los Habsburgo: el Protector de Indios en el Perú, Madrid, Ediciones de Cultura Hispánica, 1988.

Ruiz Medrano, Ethelia: Mexico's Indigenous Communities. Their Lands and Histories, 1500-2010, Boulder, University Press of Colorado, 2010.

Saint-Lu, André: «Tomás López, Erasme et Las Casas», en Las Casas indigéniste, études sur la vie et l'œuvre du défenseur des Indiens, Paris, L'Harmattan, 1982, 150-158.

Sánchez Bella, Ismael: Nuevos estudios de Derecho Indiano, Pamplona, Ediciones de la Universidad de Navarra, 1995. 
Sanchiz Ochoa, Pilar: «Cambio cultural dirigido en el siglo XVI: el oidor Tomás López Medel y su planificación de cambio para los indios de Guatemala», Ethnica, Revista de Antropología, XII, Barcelona, 1976, 128-148.

Sarabia Viejo, María Justina: «Luis de Velasco el Viejo y Francisco de Toledo: dos tipologías virreinales de la América de Felipe II», Chrónica Nova, XXVI, Granada, 1999, 333-345.

Toledo, Francisco de: Ordenanzas de don Francisco de Toledo (1569-1581), Madrid, Imprenta de Juan Pueyo, 1929.

Traslosheros, Jorge E.: Iglesia, justicia y sociedad en la Nueva España. La Audiencia del Arzobispado de México (1528-1668), México, Editorial Porrúa-Universidad Iberoamericana, 2004.

Vigil, Ralph: Alonso de Zorita. Royal Judge and Christian Humanista, 1512-1585, Norman and London, University of Oklahoma Press, 1987.

Zavala, Silvio: «El oidor Tomás López y su visión erasmista de la evangelización del Nuevo Mundo», Memoria del Colegio Nacional, VIII-1, México, 1974, $13-45$.

Zavala, «Notas sobre el oidor Tomás López», Caravelle, XXXV, Toulouse, 1980, $5-10$.

Zorraquín Becú, Ricardo: La función de la justicia en el derecho indiano, Buenos Aires, Instituto de Historia del Derecho/Imprenta de la Universidad, 1948. 